\title{
SUBJECTIVE RISK ON CARRIAGE OF HAZARDOUS LOADS WITH AUTOMOBILE TRANSPORT
}

\author{
Ivan MINEVSKI \\ Vasil Levski National Military University, Veliko Tarnovo, Bulgaria \\ ivan_minevski@abv.bg \\ Vania BANABAKOVA \\ Vasil Levski National Military University, Veliko Tarnovo, Bulgaria \\ v_banabakova@abv.bg
}

\begin{abstract}
The role of the human factor and its importance for the evaluation of the risk on carriage of hazardous loads with automobile transport is examined in the article. A system of indicators for evaluation of the risk in this direction is proposed.
\end{abstract}

KEYWORDS: indicator of risk, shazard, subjective risk

\section{Introduction}

In nowadays economical, territorial and infrastructural conditions is often forced to perform carriage of hazardous loads with automobile transport. This is determined by its priority over the other kinds of transport as: presence of a modern motor fleet which insures very quick and emergency delivery of goods and loads, high maneuverability, possibility of arranging the delivering of small shipments as for this purpose vehicles with smaller freight capacity are used in order to decrease the terms of delivery.

The choice of transport demands analyzes of the technical-economical special features of the particular kind of transport as is accented on the following characteristics: special features of the vehicles, the specificity of the exploitation, the economical efficiency and others (Banabakova, 2010; Nichev, 2011).
The automobile transport is suitable on carriage of non-durable products and products with comparatively high individual price - which are the hazardous loads. It is preferable in performing on short distances.

The computer management of the loads on carriage contributes on increasing the percentage of the automobile transport in the common structure, mostly on the railway transport account on the base of its main priority like quick delivery, high maneuverability and flexible schedule.

However, its faults should be given: dependence on the climatic factors; low capacity; low security of the delivery (Banabakova, 2010).

On this base the automobile transport is suitable on carriage of hazardous loads, but at the same time the risks are big because of the additional hazards, caused by the carried load.

While performing carriage of hazardous loads often in unforeseen situations 
incidents occur, which consequences could be tragic not only for people who are in the close proximity of the vehicle, which ensures the carriage of the load, but also for the whole area.

The aim of the present elaboration is to examine the role of the human factor and its importance for the evaluation of the risk on carriage of hazardous loads with automobile transport and to propose adequate system of indicators for evaluation of the risk.

\section{Indicators for Evaluation of the} Risk on Carriage of Hazardous Loads with Automobile Transport

Very often for realization of the deliveries the transported hazardous loads pass through town routs with high traffic, industrial sites and social buildings. Therefore the arising of the incident on carriage of these hazardous loads is precondition for appearance of sizable damages and human losses. The data from statistic studies show that the incidents on carriage of hazardous loads on the rout of movement are of the greatest frequency of appearance and the kind and the heaviness of the harm is with the highest values.

The consequences on incidents, connected with the carriage of hazardous loads could be divided into: injuries and mortal case (determined as an influence on the population); expenses for liquidation of the consequences; material damages; expenses for eventual evacuation; delay on the road; troubles and ecological damages. All these consequences have to be converted into equal units (for example money value) in order the total extent of the consequence to be determined, but to find out money equivalence of the human life is a complicated and disputable question.

The risk on carriage of hazardous loads could be examined as a function of the heaviness of the possible harm and the probability of causing of this harm (Kotik, 1987).
Analytically the risk $\mathrm{R}$ is calculated by the product:

$$
R=P(A) \cdot V(A),
$$

where: $\mathrm{P}(A)$ is the probability for arising of the harm A;

$V(A)$ - heaviness of the harm A.

This probable dependency is an impact of the accidental character of the hazard and the risk is its numerical characteristics.

Harms could be classified by different indications:

$\checkmark$ object of influence - people, environment, machines and equipment;

$\checkmark$ kind and type of the harm;

$\checkmark$ localization of the harm;

$\checkmark$ stage of the harm;

$\checkmark$ epidemiologic and a set of others.

The probability $\mathrm{P}(\mathrm{A})$ is a quality measure of the possibility of the appearance of the harm. The shown probable character of the arising hazardous events and the heaviness of the harms shows, that the determining of the risk forces utilization of the apparatus of the theory of probability and the mathematical statistics.

The heaviness of the harm $\mathrm{V}(\mathrm{A})$ is not constant and also is accidental quantity.

The risk on transport of hazardous loads with automobile transport is determined by the probability of arising of an incident which could cause harm and the extent of the arising harm.

The probability of an incident on transport of hazardous loads, in which a harm comes as a result of spilling, is an accidental event, calculated by the equation:

$$
P_{i}(I)=P_{i}(A) \cdot P(B \mid A) \cdot P(C \mid B),
$$

where: I - accidental event incident;

A - accidental event Transport road accident;

$\mathrm{B}$ - accidental event Spilling;

$\mathrm{C}$ - accidental event Fire, explosion, spreading of toxic gas in the atmosphere which causes damages. 
Since in view of the fact that the harms in consequence of the arising incident on carriage of hazardous loads could of a different character in a number of cases, it is suitable so called average risk to be determined

$$
R=\sum_{i}^{n} P_{i} \cdot V_{i},
$$

where: $P_{i}$ is probability for arising of a harm with heaviness $V_{i}$ as a result of a dangerous event or events;

$V_{i}$ - heaviness of the harm (Prakash and Manada, 2000), which depending on the kind of the harm is measured in different units (for example leva, number of disabled days, number of hospital days, surface of the contaminated territories, etc.); $\mathrm{n}$ - number of kinds of harms.

On the base of the proposed indicators for evaluation of the risk, could be derived the indicators for evaluation of the risk, connected with the human factor.

3. Indicators for Evaluation of the Risk, Connected with the Human Factor on Carriage of Hazardous Loads with Automobile Transport

The strategy of the behaviour of people in risk is described by the Structure of Burkardt (Tomov, 2003), which is shown on figure no. 1. Analyzing this scheme one comes to a conclusion that secure and protective behaviour of people depends on three factors:
$\checkmark$ stage of presumable risk;
$\checkmark$ predominant motivation;
$\checkmark$ experience at work.

The protective behaviour of people is increased by two circumstances:

$\checkmark$ when the willing result could be got without risk;

$\checkmark$ when the risky behaviour leads to an accident.

Vice versa, in the cases of reaching security in risky behaviour, protective functions of people weaken. Becoming aware of the risk influences directly on the security in the behaviour of people. In it could be selected two psychological processes - realization of the danger and evaluation of the stage of the risk.

A person, however could take active position towards the risk. More exactly, in a determinate stage it could have particular relation to hazardous situations and events and to choose such, which are determined by another probability of arising.

Initially could be chosen a riskier situation with big probability for harm as it is relied on big advantage. After that measures for decreasing the risk could be taken. With other words people, except that could generate risks, they could exclude such by appropriate protective actions. Therefore this sort of risks are also subjective, as their choice depends on people, who evaluate and accept.

The average subjective risk could be determined by the relation:

$$
R=\sum_{i}^{n} g_{i j}(W) P_{i} \cdot V_{i},
$$

where: $g_{i j}(W)$ is the probability to be chosen a situation, which is determined by the probability for arising of hazardous event $P_{J}$ and the law of the distribution of harms. 


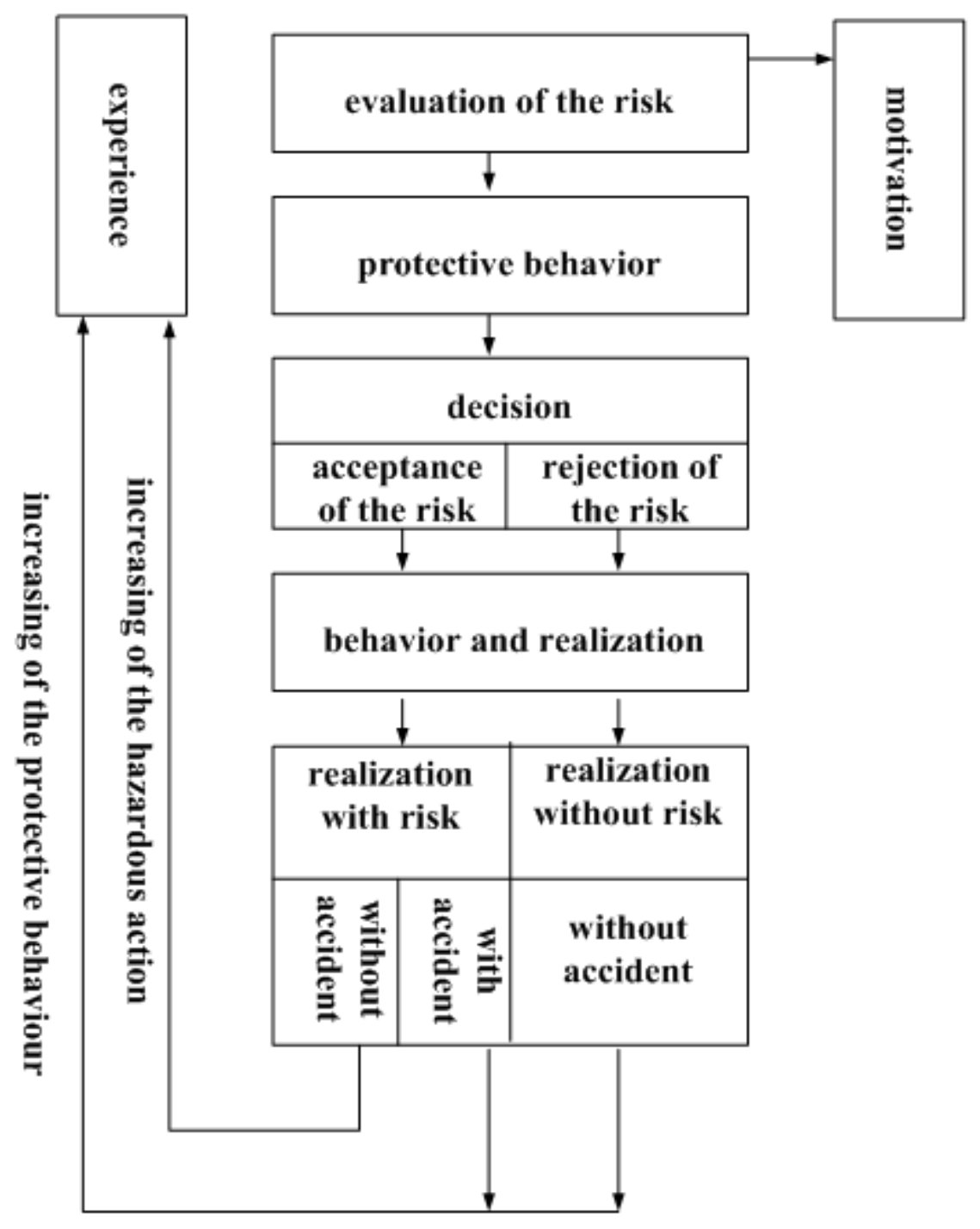

Figure no. 1: Structure of Burkardt

The shown approach about the subjective risk is illustrated on Figure no. 2, where there is possibility to be chosen a situation with smaller or a situation with bigger risk. On the figure $\mathrm{P}(\mathrm{V})$ is a symbol of the law of the distribution of the harm, when a situation could not be chosen. $\mathrm{P}_{1}$ $\left(\mathrm{W}_{1} \mathrm{~V}\right)$ is for a situation with a smaller risk, and $\mathrm{P}_{2}\left(\mathrm{~W}_{2} \mathrm{~V}\right)$ - with a bigger risk.

The differences for the risk $\Delta \mathrm{P}_{1}$ and $\Delta \mathrm{P}_{2}$ are obtained by choosing the factors $\mathrm{W}_{1}$ and $\mathrm{W}_{2}$. At $\mathrm{W}_{1}$ is chosen a hazardous situation with smaller risk and at $\mathrm{W}_{2}$ - with bigger risk for arising of harm.

From the above mentioned should be marked that "the harm factor" behaviour of the drivers of the automobile carrying hazardous loads are an important component for the evaluation and analyzes of the risk on carriage of hazardous loads. Their qualification, experience, ability to apprehend, analyze and take decision in a particular risky situation, determine at a great stage the reduction of the risk at acceptable limits. The process of driving the motor vehicle, carrying a hazardous load is connected with the receiving of the most significant information, as it concerns the vehicle itself and the road situation, of a great importance are the quality of the apprehension and the attention, of the main memory of the individual, as whole or in particular of the logic intellect. 


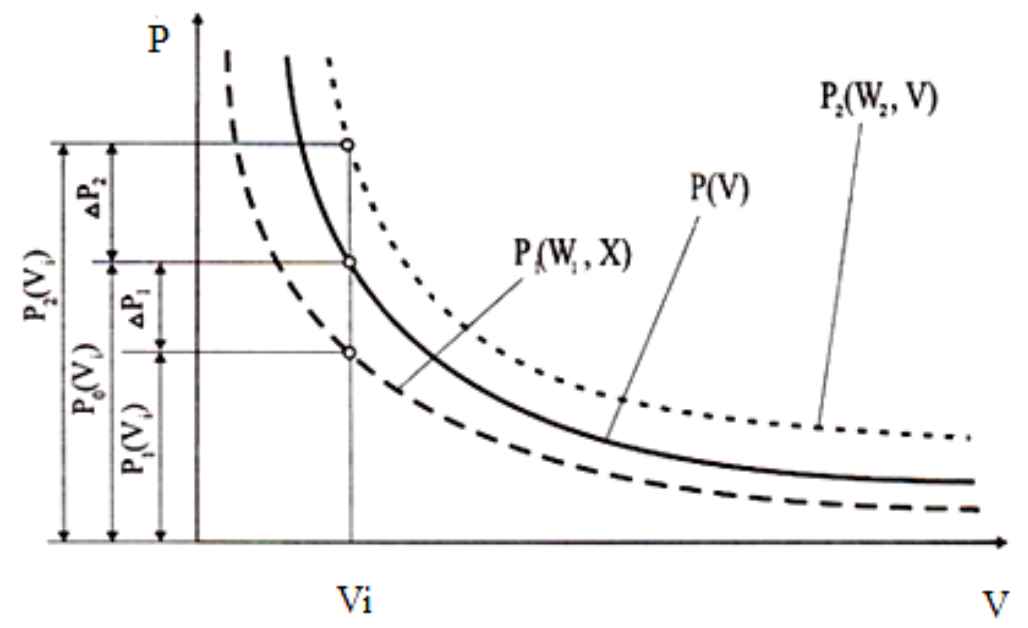

Figure no. 2: Difference in the risk for the cases of choice or without choice of the hazardous situation or even

The interdependence between the apprehension and the ability for receiving and revision of the information is connected with the necessity of determining the significant from the complex visual information, received by the driver on the road. While driving automobiles, carrying hazardous loads, is necessary to have the necessary qualities of apprehension, as the most important from them are: stability, distribution and switching over. The high stability is necessary as the driver must follow continuously the incoming information about the road situation (traffic, condition on the roadway, climatic changes, etc.), technical condition of the automobile and the observance of all general and specific requirements concerning safety carriage of hazardous loads. The correct distribution of the attention guarantee the ability for simultaneous implementation of one or more activities. While driving the automobile the driver should simultaneously follow the condition of the carried hazardous load and handle with the control systems. The lack of good distribution could be compensate with good switching over, as the objects are covered consecutively and not simultaneously.

In the process of taking a decision from the driver, except the potential qualities are included much clearly also his personal characteristics. In the cases when the mistakes of the driver are not connected with the problems as a quality from the cognitive sphere, the taken decision is an indicator for the level of development of personal quality. The interdependence between the personal quality and the safety of the traffic of the automobile transport is proved by numerous investigations. One of the personal qualities of the drivers, object of study is the emotional stability. Another personal quality object of numerous studies in connection with the safety of the movement is the aptitude for undertaking a risk.

\section{Conclusions}

At the bases of the proposed scheme for evaluation of the risk on carriage of hazardous loads by means of automobile transport the following conclusions could be made.

$\checkmark$ The arising of an incident on automobile carriage of hazardous loads could drive to significant harms on the infrastructure, ecology and especially on people's health and life.

$\checkmark$ The behaviour of the driver on carriage of hazardous loads could be examined multilaterally determinatively 
from the individual personal qualities, formed under the influence of the natural and social media, gained at the time of preparing of the knowledge, abilities and habits for driving of the automobile transporting hazardous loads and other factors.

$\checkmark$ The proposed system of indicators for evaluation of the risk on carriage of hazardous loads with automobiles has as an aim beforehand measurement of the risk and outlines preventive measures for its minimization.

As a conclusion we have to generalize that a big part of the drivers cannot, in a sufficient part, realize the potential risk, existing in nowadays traffic. The possible hazard is often not appreciated properly, which often leads to incidents. For safety behaviour while on the road of importance is not one, but a complex of personal characteristics of the drivers, who carry hazardous loads.

\section{REFERENCES}

Banabakova, V. (2010). Business logistic, Veliko Tarnovo: Faber Publishing House, 80.

Kotik, M. (1987). Psychology and Safety, Talin: Valgus.

Nichev, N. (2011). Theoretical foundations of military logistics - organization of logistical support, V. Tarnovo: "Vasil Levski" National Military University, 110-113.

Prakash, B. \& Manada R. A. (2000). Simulation study for hazardous materials transportation risk, Assesments for the Degree of Master of Applied Science, Quebec, Canada: Concordia University, Montreal.

Tomov, V. (2003). Theory of the risk, Rousse: RU “Angel Kanchev”. 